\title{
Sorptive testing of mortars with varying water-cement ratios
}

\author{
Agata Stolarska ${ }^{1, *}$, Szymon Ciborowski ${ }^{1}$ \\ ${ }^{1}$ Department of Building Physics and Building Materials, Faculty of Civil Engineering and \\ Architecture, West Pomeranian University of Technology Szczecin, al. Piastów 50, 70-311 \\ Szczecin, Poland
}

\begin{abstract}
The article presents the results of studies on sorption performed on three samples of mortars with similar density of about $2,000 \mathrm{~kg} / \mathrm{m}^{3}$. The tested mortars differed in their water-to-cement ratio. Three levels of $w / c$ ratio were adopted that were respectively: $0.5 ; 0.55$ and 0.6 . The prepared mortars were cut into samples with a thickness of $1 \mathrm{~cm}$, dried to constant weight at a temperature of $105^{\circ} \mathrm{C}$ and insulated on the side surface with silicone. The experiment was carried out at a temperature of $25^{\circ} \mathrm{C}$ and at six different levels of relative humidity $\varphi \approx 12,33,54,76,85,98 \%$. Relative humidity was provided by saturated solutions of the appropriate salts: $\mathrm{LiCl}$ $(\varphi \approx 12 \%), \mathrm{MgCl}_{2}(\varphi \approx 33 \%), \mathrm{Mg}\left(\mathrm{NO}_{3}\right)_{2}(\varphi \approx 53 \%), \mathrm{NaCl}(\varphi \approx 76 \%), \mathrm{KCl}$ $(\varphi \approx 85 \%), \mathrm{K}_{2} \mathrm{SO}_{4}(\varphi \approx 98 \%)$. The adopted level of temperature and range of relative humidity meet the hygrothermal conditions which tend to affect the cement mortar in real life. The long-term measurement results were used to assess the behaviour of the tested mortars under various conditions of moisture and to determine the equilibrium sorptive humidity.
\end{abstract}

\section{Introduction}

Sorptivity of building materials varies within wide limits. This parameter depends mainly on the type of material, its structure, porosity, density, composition, mix ratio, additives and admixtures, technology of manufacture and the hygrothermal conditions, i.e., relative humidity and temperature.

A number of scientific centers carry out studies concerning the processes of moisture sorption. As a rule, these studies are based on the determination of the adsorbate mass on the basis of accurate measurements of the sample mass before, during and after the experiment. The standard method for determining sorptive properties is presented in the norm [1]. Its shortcomings as well as the application of a new method that reduces the measurement times are presented in $[2,3]$. On the other hand, [4,5] discuss the applicability of the DVS method (Dynamic Vapor Sorption) for the determination of sorption [4] and desorption [5] isotherms, pointing to the fact that the DVS method yields values of equillibrium humidity similar to the traditional method, but only in the range of relative humidity of $\mathrm{RH}<75 \div 85 \%$. In turn, the authors of $[6,7]$ demonstrate an innovative

*Corresponding author: siwinska@zut.edu.p1 
method of measurements using the so-called microcalorimeter which allows for a thermodynamic characterization of the sorption process.

However, regardless of the method, the obtained sorption isotherms of water vapor significantly contribute to the current knowledge, among other things, on the porous nanostructure of cement materials and are an important component of the modern strength calculations. Work [8] describes two newly developed multi-chamber apparatuses for studying hardened cement materials. The tests conducted focused especially on the adsorption and desorption of hardened cement paste and concrete in a wide range of temperatures: from $23^{\circ} \mathrm{C}$ to $80^{\circ} \mathrm{C}$. The experiments confirmed the monotonic sorption hysteresis reduction that occurs with increasing temperature. Moreover, the influence of temperature and humidity on the kinetics of the sorption process was examined. Evidence was presented confirming the role of changes in microstructure in the observed process kinetics.

Cement-based materials were also the subject of studies presented in [9]. Researchers used a dynamic method of sorption measurements of paste based on the CEM I Portland cement with the addition of slag and silica at two values of the water/solid ratio: 0.5 and 0.4 . The tests were carried out at a temperature of $25^{\circ} \mathrm{C}$. The obtained results were used to determine diffusivity. The researchers observed that the kinetics of water vapor sorption in the analysed materials could not be fully described by the Fick's law. The sorption curves pointed to the fact that the sorption of water vapor is the result of two processes. One of them is the macrodiffusion to the sample that can be evaluated on the basis of the first linear part of the sorption curve. The other process occurs in longer time intervals and is related to the availability of free space in the material.

The issue of water sorption by superabsorptive polymers in cement paste was tackled by the authors of [10]. Sorption kinetics was evaluated on the basis of neutron radiography on the samples of cement paste of $w / c$ ratio $=0.25$ and 0.50 , and cement paste containing silica fume with $w / c=0.42$.

Types of pastes containing superabsorptive polymers were also the subject of analysis in [11]. In it, pastes with low water-to-cement ratio were analysed. The issue approached in the article is associated with the prediction of the impact of internal hardening both on the material behaviour during maturing and on its final physical properties.

On the other hand, article [12] presents a new model and methodology for prediction of microstructure and the subsequent isotherm of water vapor of hardened cement paste. The proposed model develops along with hydration and constitutes a rational basis for prediction and application in numerical moisture simulations.

The paper [13] shows the results of investigations on sorption and desorption of hardened cement paste with the use of saturated salt solutions. The work focuses particularly on the impact of the $w / c$ ratio on the sorptive and microstructural properties for a wide range of cement pastes and concretes.

The sorption of pastes examined in the present paper was also the subject of articles by the authors of [14-17]. In turn, works [18-23] studied cement mortars with $w / c$ ratio $=0.50,0.65,0.80$ in the processes of sorption and desorption. Different methods of calculation were used based on the inverse problem so that, having recorded the kinetics of the sorption and desorption processes, the diffusion coefficient variability of the tested mortars in a wide range of humidity could be determined.

\section{Materials and methods}

The subject of the planned experiment were cement mortars made on the basis of the CEM I 42.5 R cement and fine sand. Mortars were differentiated by means of their $w / c$ ratios. Three levels of $w / c$ ratio were adopted: $0.5 ; 0.55$ and 0.6 . The experiment took place in 
several stages. First, the mortars were prepared. The measurements performed concerned three cement mortars with ingredient proportions: CM1 (3:1:0.5), CM2 (3:1:0.55), CM3 (3:1:0.6).

The molds used in the process measured $30 \times 10 \times 10 \mathrm{~cm}$. After 24 hours of hardening, the molds were removed and the mortars were stored in a humidity chamber for the next 27 days. The ready materials were then wet cut using a diamond blade into $1 \mathrm{~cm}$ thick samples. Next, the samples were dried to constant weight at a temperature of $105^{\circ} \mathrm{C}$ (Fig. 1) and insulated with silicone on the side surface. The accurate insulation of the sides of samples allowed a one-way humidity exchange in the process of sorption (only via the face surfaces).

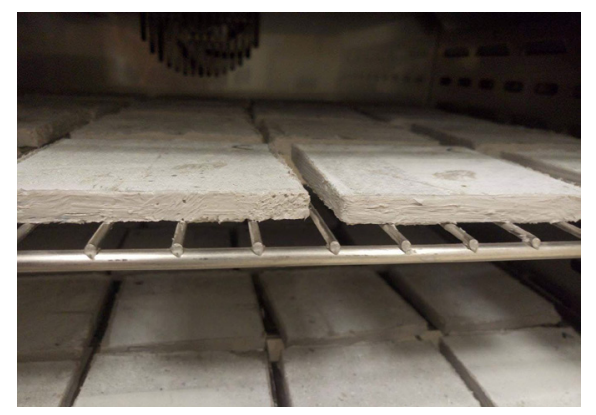

Fig. 1. Mortar samples in the drying process [24].

On the basis of the inventory made, the volume density of samples was determined [24]. The average density of individual groups of samples along with the standard deviations are summarized in Table 1 . The data shows the impact of the $w / c$ ratio on the values of the resulting densities. It was observed that with the increasing addition of water the density of the tested mortars was decreasing.

Table 1. The average density of the tested mortars along with the standard deviations [24].

\begin{tabular}{|c|c|c|}
\hline Material & $\boldsymbol{\rho}\left[\mathbf{g} / \mathbf{c m}^{\mathbf{3}}\right]$ & $\boldsymbol{s}_{\boldsymbol{\rho}}\left[\mathbf{g} / \mathbf{c m}^{\mathbf{3}}\right]$ \\
\hline $\mathrm{CM} 1$ & 2.07 & 0.042 \\
\hline $\mathrm{CM} 2$ & 2.02 & 0.017 \\
\hline $\mathrm{CM} 3$ & 1.97 & 0.021 \\
\hline
\end{tabular}

The experiment itself was carried out at a temperature of $25^{\circ} \mathrm{C}$ and at six different levels of relative humidity $\varphi \approx 12,33,54,76,85,98 \%$. Relative humidity was provided by saturated solutions of the appropriate salts: $\mathrm{LiCl}(\varphi \approx 12 \%), \mathrm{MgCl}_{2}(\varphi \approx 33 \%), \mathrm{Mg}_{\left(\mathrm{NO}_{3}\right)_{2}}$ $(\varphi \approx 53 \%), \mathrm{NaCl}(\varphi \approx 76 \%), \mathrm{KCl}(\varphi \approx 85 \%), \mathrm{K}_{2} \mathrm{SO}_{4}(\varphi \approx 98 \%)$. The adopted level of temperature and range of relative humidity meet the hygrothermal conditions which tend to affect the construction mortar in real life.

The examination proper of the sorptive parameters consisted in placing the samples in tightly sealed containers over saturated salt solutions. In each level of relative air humidity there were three samples of the given material. A total of 54 samples were tested. Fig. 2 shows the interior of the container with samples. The measurements consisting in recording changes in the sample mass lasted for 3.5 months. The intervals between the measurements, initially lasting several hours, over time were increased to 7 days. The measurements were being carried out until reaching the moisture equillibrium state in all samples stored in given heat and moisture conditions. The sorption process took place most intensively during the initial stage, i.e. approximately in the first 7 days. After this period, only slight sorptive humidity increases were observed. The results obtained for the 
equillibrium state were used to determine sorptive humidity $w$ [\%] expressed as the percentage of moisture referred to the dry sample weight.

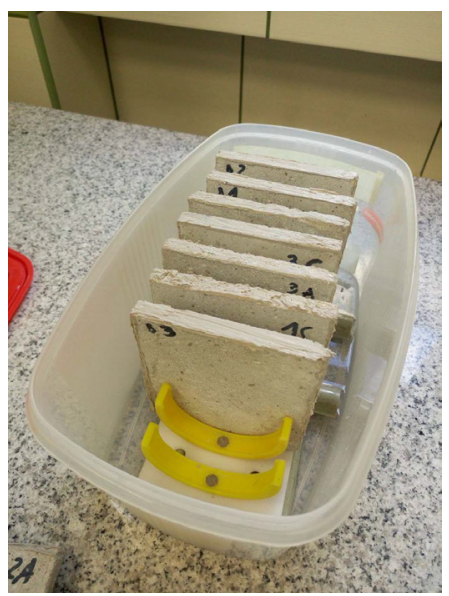

Fig. 2. The samples in the container above the solution [24].

\section{Results and discussions}

Long-term measurements allowed for a graphical representation of the changing weight of samples over time. The averaged graphs showing the process kinetics are presented in Fig. 3-5. While initially the samples absorbed moisture at a fast pace, the process slowed down with every next hour. It took place with the greatest intensity in the samples of mortars placed in higher relative air humidity environments, i.e. $85 \%$ and $98 \%$. At lower levels of relative humidity, i.e., at $54 \%$, the process was stabilised more quickly. Similar dependencies were observed for all three studied mortars.

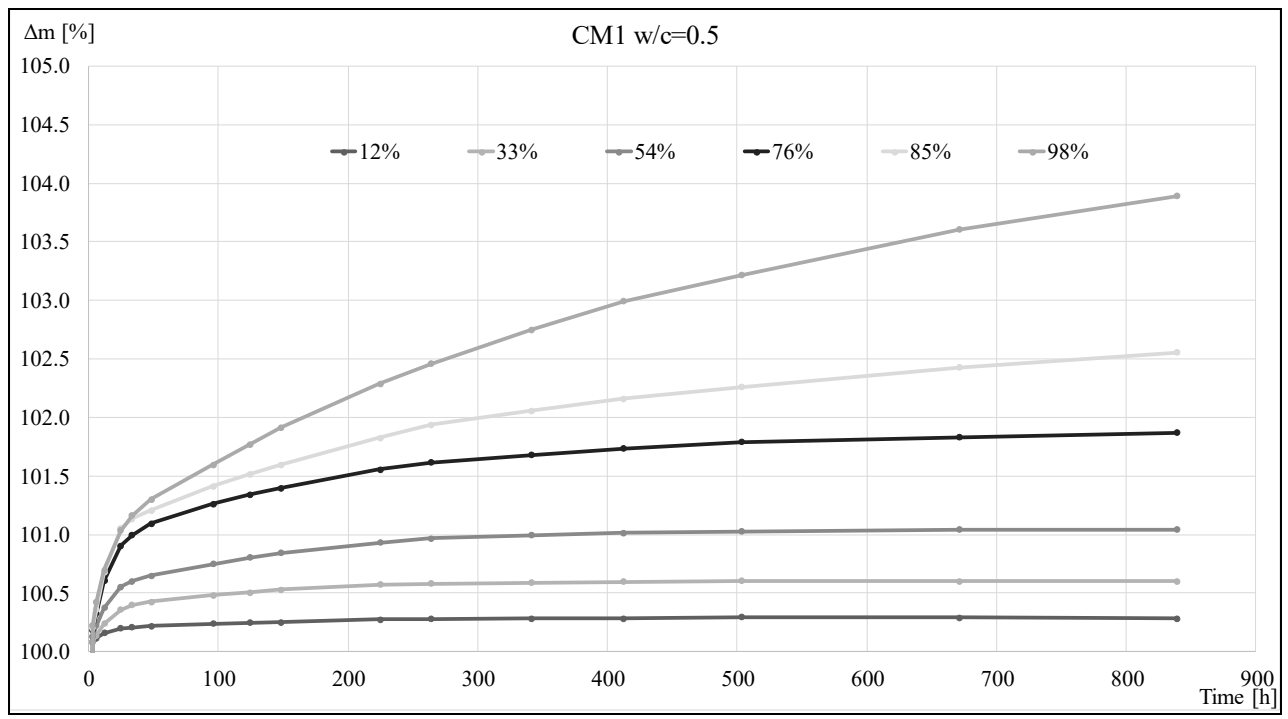

Fig. 3. Kinetics of the sorption process of CM1 cement mortar of $w / c$ ratio $=0.5$ in different humidity environments. 


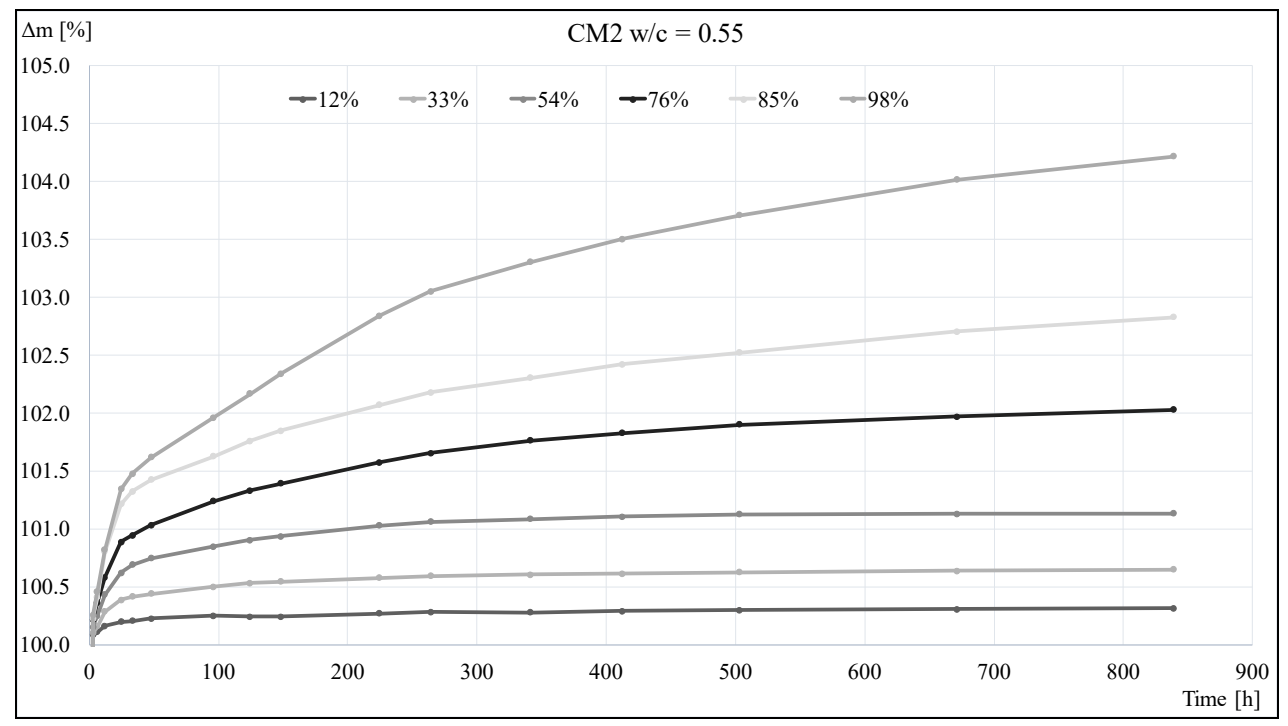

Fig. 4. Kinetics of the sorption process of $\mathrm{CM} 2$ cement mortar of $w / c$ ratio $=0.55$ in different humidity environments.

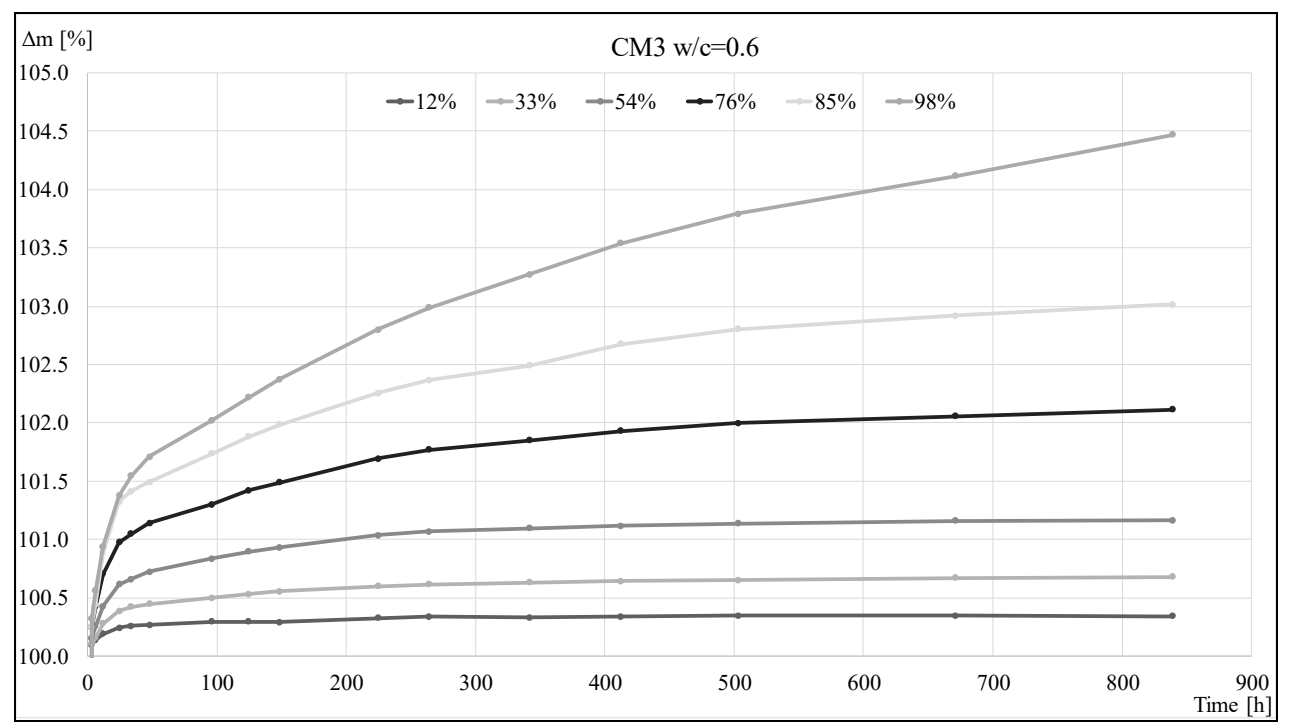

Fig. 5. Kinetics of the sorption process of $\mathrm{CM} 3$ cement mortar of $w / c$ ratio $=0.6$ in different humidity environments.

In turn, Fig. 6 illustrates the influence of the $w / c$ ratio on the intensity of the process at different relative air humidity values. The results presented in Fig. 6 provide the same data as in Fig. 3-5, however grouped in a different way to emphasise $w / c$ influence. In the initial stage of the process, no significant differences between the kinetics of the process in different types of mortars were observed. The influence of the $w / c$ ratio occurs only after about 24 hours at a humidity of $12 \%$ and after about 48 hours at higher humidity values. Moreover, it was observed that samples of higher $w / c$ ratio and, therefore, of lesser density absorbed more moisture at any humidity level. The decrease in the $w / c$ ratio resulted in an increase in density and contributed every time to a reduction of the sorbed moisture during the process. Similar dependencies were observed for all humidity conditions. 

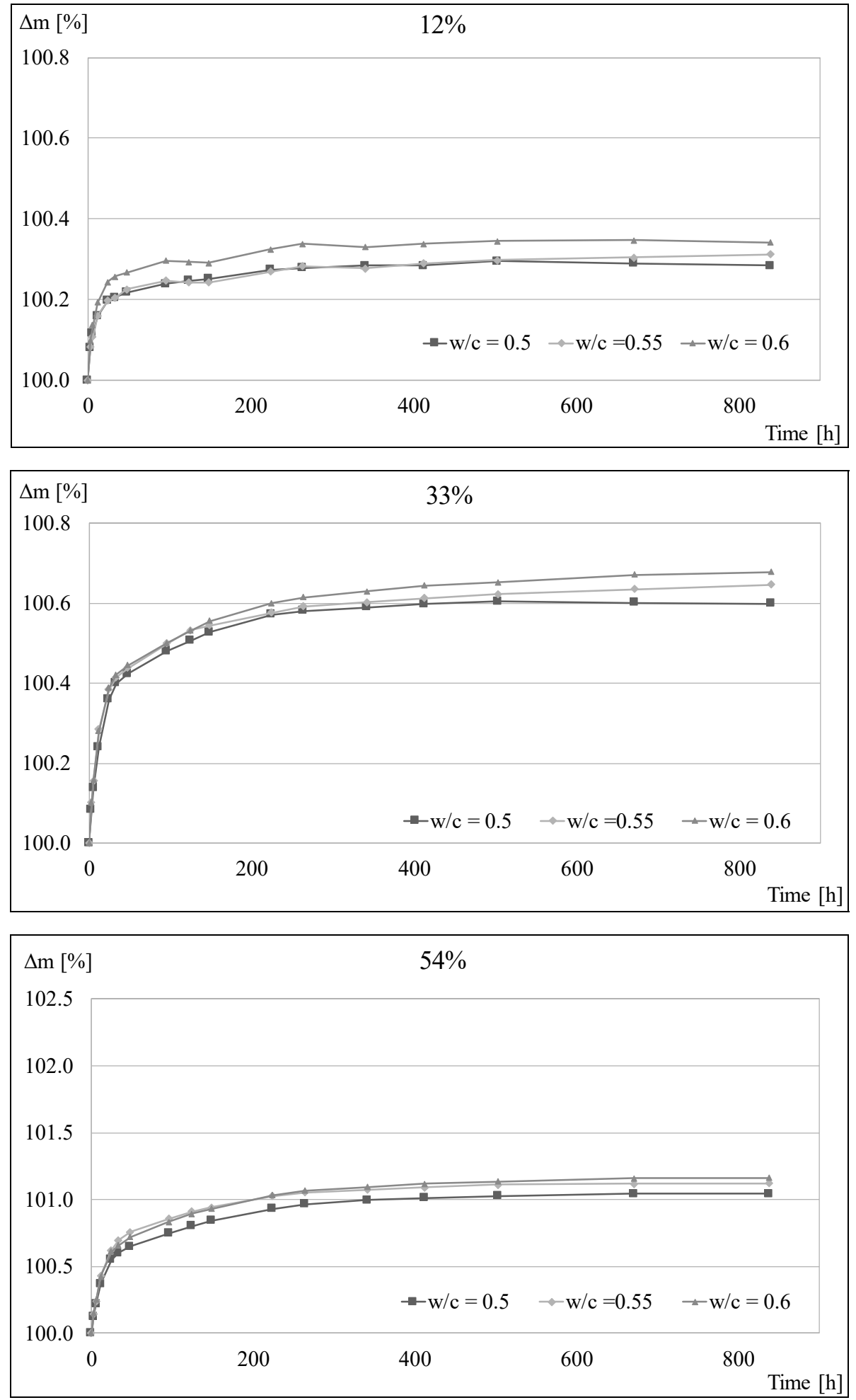

Fig. 6. Kinetics of the sorption process of cement mortars in different humidity environments [24]. 

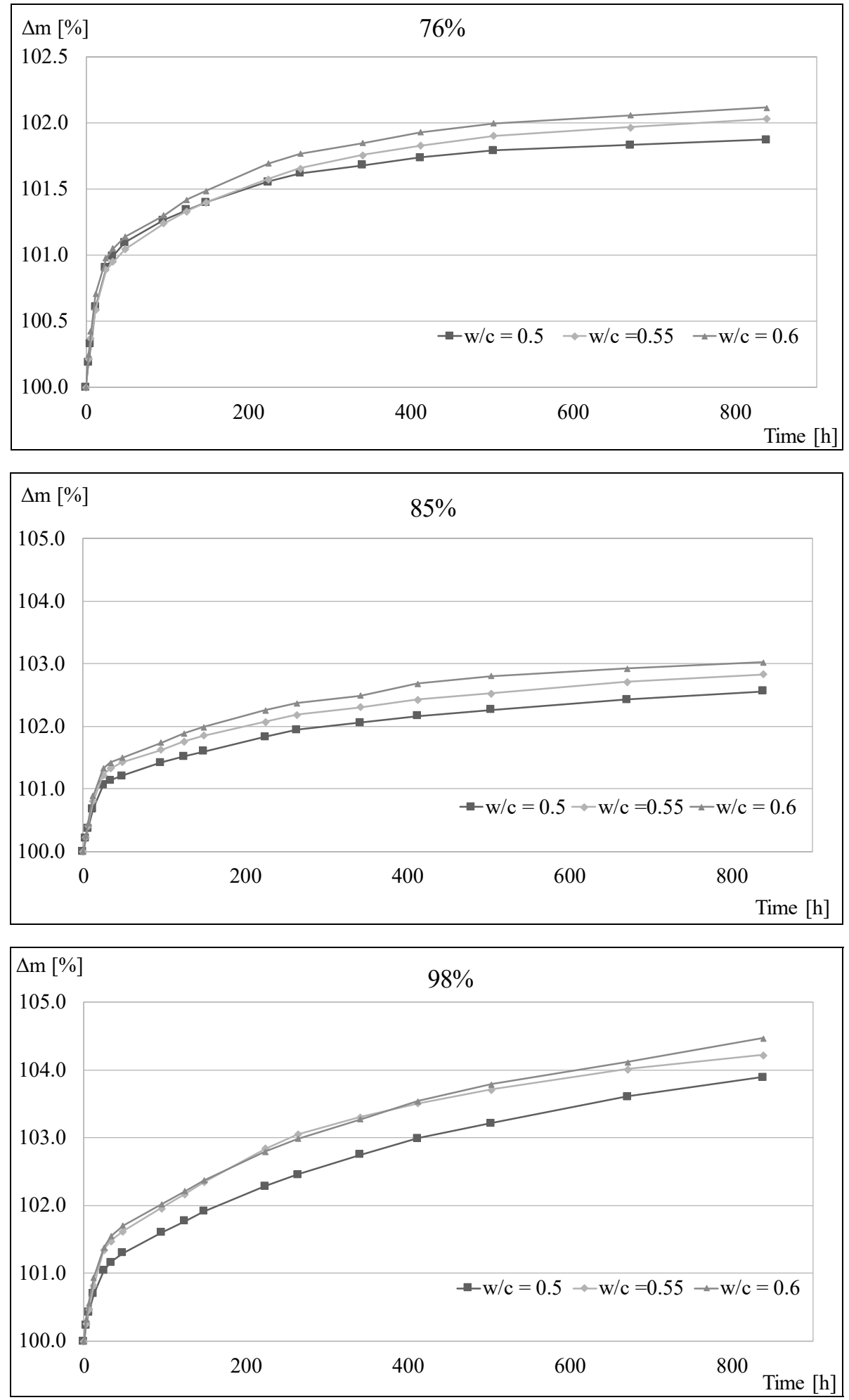

Fig. 6. (cont.) Kinetics of the sorption process of cement mortars in different humidity environments [24]. 
On the basis of long-term records of weight changes of samples in different climatic conditions the equillibrium sorptive humidity was calculated. The average stabilised sorptive humidity for the three tested mortars is shown in Table 2 and represented graphically in Fig. 7. In each of the 6 climatic conditions, the stabilised sorptive humidity was determined as the arithmetic mean of three samples. In case of relative humidity of air above $76 \%$, the samples have not yet reached a moisture equilibrium level and require further conditioning.

Table 2. Average stabilized sorptive humidity [24].

\begin{tabular}{|c|c|c|c|}
\hline \multirow{2}{*}{$\boldsymbol{\varphi}[\%]$} & $\begin{array}{c}\text { CM1 } \\
(\boldsymbol{w} / \boldsymbol{c}=\mathbf{0 . 5})\end{array}$ & $\begin{array}{c}\text { CM2 } \\
(\boldsymbol{w} / \boldsymbol{c}=\mathbf{0 . 5 5})\end{array}$ & $\begin{array}{c}\mathbf{C M 3} \\
(\boldsymbol{w} / \boldsymbol{c}=\mathbf{0 . 6})\end{array}$ \\
\cline { 2 - 4 } & \multicolumn{3}{|c|}{$\boldsymbol{w}[\mathbf{\%}]$} \\
\hline 12 & 0.283 & 0.311 & 0.342 \\
\hline 33 & 0.599 & 0.647 & 0.678 \\
\hline 53 & 1.044 & 1.122 & 1.163 \\
\hline 76 & 1.871 & 2.030 & 2.115 \\
\hline 85 & 2.554 & 2.830 & 3.016 \\
\hline 98 & 3.894 & 4.218 & 4.471 \\
\hline
\end{tabular}

The greatest sorptive humidity of all the tested materials was achieved by cement mortar CM3 in all six humidity conditions. The maximum value was observed at $\varphi \approx 98 \%$ and it amounted to $4.471 \%$. The lowest sorptivity among the tested mortars at all levels of relative humidity was demonstrated by CM1, achieving the least moisture content at humidity of $\varphi \approx 12 \%-0.283 \%$.

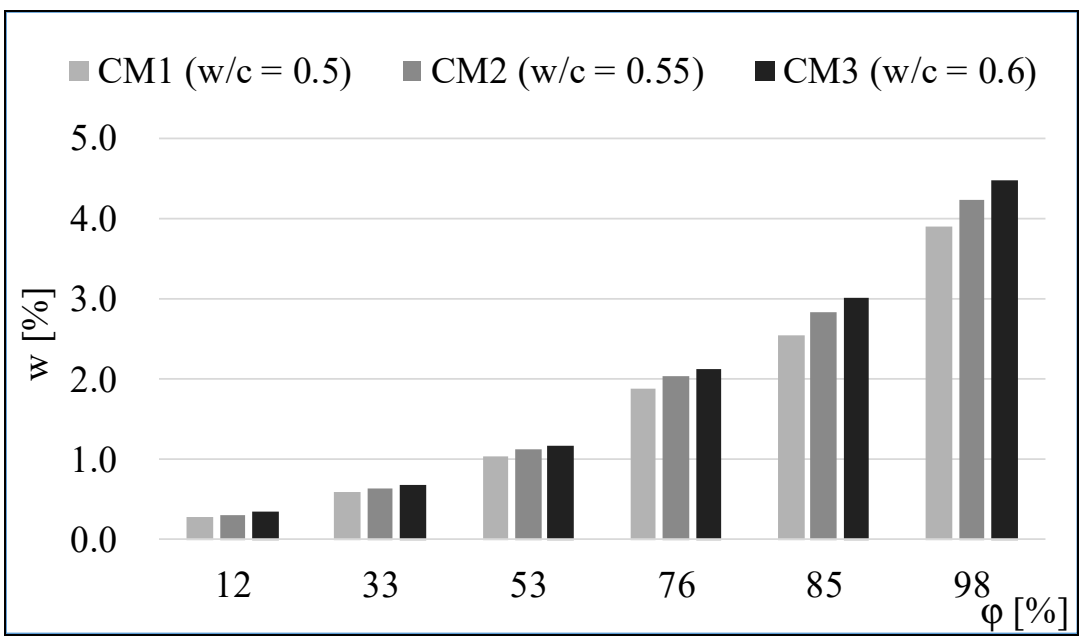

Fig. 7. The average sorptive humidity of mortars [24].

The results obtained clearly indicate the impact of the adopted ingredient proportions, especially the $w / c$ ratio, on the obtained value of sorptive humidity. CM1, with the lowest $w / c=0.5$ ratio and highest density, reached the lowest sorptive humidity values at all levels of relative air humidity, while CM3, with increased $w / c=0.6$ and lowest density, absorbed the highest amount of moisture. The values obtained for CM2 mortar stand between the other two groups in all instances. 


\section{Conclusions}

The article presents the results of studies on the sorption of cement mortars of various water-to-cement ratios. The analysis of the humidity values obtained clearly indicates that the mortar with the largest $w / c$ ratio $=0.6$ and lowest density sorbed the highest amount of moisture. The analysis also makes clear that the kinetics of the process depends on the relative humidity of the environment in which the tested mortar is located, as evidenced by the increase in moisture content with increasing relative humidity. In addition, another factor differentiating the amount of moisture is the ingredient proportion of the mortars; in this case, the water-to-cement ratio.

The presented results are only a part of a wider analysis. Further research to study the porosity of mortars with a variable $w / c$ ratio, as well as further conditioning of samples athumidity above $76 \%$ until reaching the state of humidity equilibrium is planned.

The results of tests and analyses point to a need for further studies on sorption, as they may fill the gaps in the databases of the properties of the current or modified existing building materials. The parameters of porous and hygroscopic building materials are closely related to their absorption properties. The factor which also influences their weight, mechanical, acoustic and thermal properties as well as strength is humidity. In view of this, a continuous monitoring of moisture levels in construction elements is recommended.

The practical application of the study results involves, in particular, improvements in the strength of cement-based structures and optimization of concrete mixtures.

\section{References}

1. PN-EN ISO 12571:2002 Hygrothermal performance of building materials and products - determination of hygroscopic sorption properties

2. R. Plagge, G. Scheffler, J. Grunewald, Measurement of water retention and moisture conductivity at transient conditions. Research in Building Physics and Building Engineering, 129-136 (2006)

3. G. Scheffler, R. Plagge, J. Grunewald, P. Häupl, Evaluation of instantaneous profile measurements indicating dependencies of moisture transport on hysteresis and dynamics. Research in Building Physics and Building Engineering, 121-128 (2006)

4. H. Garbalińska, M. Bochenek, W. Malorny, J. Von Werder, Comparative analysis of the dynamic vapor sorption (DVS) technique and the traditional method for sorption isotherms determination - Exemplified at autoclaved aerated concrete samples of four density classes, Cement Concrete Res, 91, 97-105 (2017)

5. H. Garbalińska, M. Bochenek, Experimentelle Ermittlung der Desorptionsisothermen von Porenbeton unterschiedlicher Dichte mit der Standardmethode SSS und mit der DVSTechnik, Bauphysik, 39, 191-196 (2017)

6. N. Markova, E. Sparr, L. Wadsö, On application of an isothermal sorption microcalorimeter. Thermochim Acta 374, 93-104 (2001)

7. I. Wadsö, L. Wadsö, A new method for determination of vapour sorption isotherms using a twin double microcalorimeter. Thermochim Acta 271, 179-187 (1996)

8. J. M. de Burgh, S. J. Foster, Influence of temperature on water vapour sorption isotherms and kinetics of hardened cement paste and concrete, Cement Concrete Res, 92, 37-55 (2017)

9. M. Saeidpour, L.Wadsö, Evidence for anomalous water vapor sorption kinetics in cement based materials, Cement Concrete Res, 70, 60-66 (2015)

10. C. Schroefl, V. Mechtcherine, P. Vontobel, J. Hovind, E. Lehmann, Sorption kinetics of 
superabsorbent polymers (SAPs) in fresh Portland cement-based pastes visualized and quantified by neutron radiography and correlated to the progress of cement hydration, Cement Concrete Res, 75, 1-13 (2015)

11. M. Wyrzykowski, P. Lura, F. Pesavento, D. Gawin, Modeling of internal curing in maturing mortar, Cement Concrete Res, 41(12), 1349-1356 (2011)

12. J. M. de Burgh, S. J. Foster, H. R. Valipour, Prediction of water vapour sorption isotherms and microstructure of hardened Portland cement pastes, Cement Concrete Res, 81, 134-150 (2016)

13. V. Baroghel-Bouny, Cement Concrete Res, 37, 414-437 (2007)

14. M. Janz, (Moisture transport and fixation in porous materials at high moisture levels, Lund, 1997)

15. B. F. Johannesson, Cement Concrete Res, 32, 955-962 (2002)

16. R. M. Espinosa, L. Franke, 36, 1969-1984 (2006)

17. A. Stolarska, H. Garbalińska, Heat Mass Transfer, 53(5), 1603-1617 (2017)

18. H. Garbalińska, 45, 1353-1357 (2002)

19. H. Garbalińska, Heat Mass Transfer, 40, 963-972 (2004)

20. H. Garbalińska, Cement Concrete Res, 36, 1294-1303 (2006)

21. H. Garbalińska, S. J. Kowalski, M. Staszak, Cement Concrete Res, 40, 752-762 (2010)

22. H. Garbalińska, S. J. Kowalski, M. Staszak, Transport Porous Med, 85, 79-96 (2010)

23. H. Garbalińska, S. J. Kowalski, M. Staszak, Int J Heat Mass Tran, 56, (1-2), 212-222 (2013)

24. S. Ciborowski, (Comparative analysis of the kinetics of humidity absorption for compounds of variable water/cement ratio. West Pomeranian University of Technology Szczecin, engineering work, promoter dr inż. A. Stolarska, Szczecin, 2017) 